The University of Maine

\title{
DigitalCommons@UMaine
}

Maine-Syracuse Longitudinal Papers

Maine-Syracuse Longitudinal Study

2009

\section{Predicting conversion to mild cognitive impairment: Some error is the price of much truth}

Merrill F. Elias

University of Maine,mfelias@maine.edu

Adam Davey

Temple University

Follow this and additional works at: https://digitalcommons.library.umaine.edu/

longitudinal_papers

\section{Repository Citation}

Elias, Merrill F. and Davey, Adam, "Predicting conversion to mild cognitive impairment: Some error is the price of much truth" (2009). Maine-Syracuse Longitudinal Papers. 44.

https://digitalcommons.library.umaine.edu/longitudinal_papers/44

This Article is brought to you for free and open access by DigitalCommons@UMaine. It has been accepted for inclusion in Maine-Syracuse Longitudinal Papers by an authorized administrator of DigitalCommons@UMaine. For more information, please contact um.library.technical.services@maine.edu. 


\title{
Predicting conversion to mild cognitive impairment
}

\author{
Some error is the price of much truth
}

Merrill F. Elias, PhD, $\mathrm{MPH}$

Adam Davey, PhD

Address correspondence and reprint requests to Professor Merrill F. Elias, Department of Psychology, University of Maine, 5714 Little Hall, Orono, ME 04469-5742

mfelias@aol.com

Neurology $y^{\circledR} 2009 ; 73: 1432-1433$
Most individuals sustain healthy cognitive performance for a large portion of their life span. A smaller proportion progresses to mild cognitive impairment (MCI). Aside from its impact on quality of life, conversion to $\mathrm{MCI}$ is a risk factor for progression to dementia.

Amnestic MCI (aMCI) is a subtype of MCI where memory deficits, particularly memory for specific past events involving the self (episodic memory), are an early and predominant indicator of impending or existing MCI. A report from the Oxford Study to Investigate Memory and Ageing (OPTIMA) in this issue of Neurology ${ }^{\circledR}$ indicates that verbal expression (expressive language) and learning deficits predict aMCI. ${ }^{1}$ The language deficit finding is consistent with previous work with dementia as the major outcome. ${ }^{2}$ With regard to the finding for learning deficit, it is important to note that learning and memory are inherently inseparable constructs when measured with clinical tests.

Survival analysis was used to predict time to progression to aMCI. Careful analyses demonstrate a high degree of agreement between results obtained using 3 different approaches to predicting conversion, and the article also presents important detailed data on probability of conversion beginning at age 70 years.

A cohort of 241 cognitively intact elderly volunteers was followed for up to 20 years with assessments of cognitive abilities using the Cambridge Examination for Disorders for the Elderly, which includes the Cambridge Cognitive Examination (CAMCOG). ${ }^{3}$ Ninety-one of the participants converted to aMCI. Language expression and learning were consistent predictors of time to conversion at the 0 - to 2-year interval, with age entering consistently at prediction intervals beyond 6 years from baseline. Time to conversion to aMCI was $15 \%$ shorter for each point lower on learning scores and 17\% shorter for each point lower on expressive language scores.

This is a highly performing sample (scores on language expression and learning/memory were $\geq 19$ and 14 of possible 21 and 17 points, respectively), with $80 \%$ of the healthy controls drawn from the 2 highest social classes (British ranking system). Language expression may not be as important a predictor of aMCI in a more diverse sample where the range of cognitive test scores is less restricted. This study limitation does not detract from the importance of its findings. Intellectually advantaged individuals are not spared the indignities of MCI.

Several research questions come to mind. 1) Would expressive language ability remain a predictor of conversion to MCI in a study where there was a greater burden of vascular risk factors? Vascular cognitive impairment often involves multiple deficits in cognition; language expression and memory may not be predominant among them. ${ }^{4}$ 2) Would the same results be obtained if criteria for subject selection were more independent of the predictors of conversion to MCI? Predictors of MCI depend on how MCI is defined..$^{5}$ In the OPTIMA study, learning is both a predictor of conversion and a criterion for subject selection. 3) Which time-varying covariates further predict conversion beyond the baseline predictors of the OPTIMA study? Cognition and cardiovascular disease (CVD) risk factors are not static. Probabilities of conversion to MCI will almost certainly depend on initial levels of performance. Lower scoring individuals have less reserve capacity to buffer risk factors that are themselves changing over time. Work in this area could be further advanced through statistical consideration of covariate data from each observational period, especially time-varying cardiovascular risk factors. ${ }^{6}$ In the OPTIMA study, none of the traditional CVD risk factors, other than age and APOE e4 at some specific follow-up periods,

See page 1436

e-Pub ahead of print on September 30, 2009, at www.neurology.org.

From the Department of Psychology and Graduate School of Biomedical Sciences (M.F.E.), University of Maine, Orono, ME; and Department of Public Health (A.D.), Temple University, Philadelphia, PA.

Preparation of this editorial was supported by grants 1R01-HL67358 and 1R01-HL081290 from the National Heart, Lung, and Blood Institute and 1P01-AG17553 from the National Institute on Aging, NIH. The opinions and conclusions reached are not approved by the NIH.

Disclosure: Author disclosures are provided at the end of the editorial. 
emerged consistently as predictors of MCI. Diabetes mellitus, a strong predictor of MCI, ${ }^{6}$ was not included in the OPTIMA regression models, but hypertension and plasma homocysteine were. Two recent studies from the OPTIMA group indicate that blood pressure and homocysteine are predictors of dementia. ${ }^{7,8}$ Risk factors for CVD might have emerged as significant predictors of MCI as timevarying covariates, or had they not been competing with cognitive variables.

Final considerations relate to measurement. Clinical tests are not pure measures of the abilities (cognitive constructs) they purport to measure. ${ }^{9}$ As noted previously, the CAMCOG learning test is dependent on memory. Factor analysis can help to identify relatively independent cognitive constructs measured by a test battery. Earlier factor analysis of CAMCOG identified a language expression factor and memory factors, but no learning factor. ${ }^{2}$ Consequently, pending factor analyses establishing otherwise, we suggest that learning dependent on memory was the second major predictor of conversion to aMCI in OPTIMA. This has important implications for early diagnosis of aMCI and should be explored in future studies using multiple indices of learning varying with respect to demands on memory.

In all scientific undertakings, "some error is the price of much truth." 10 Prediction of MCI is an imprecise science. Within these constraints, the OPTIMA study provides impressive evidence for the role of expressive language in conversion to $\mathrm{aMCI}$ and encourages further work on the precise role of memory in the context of learning.

\section{ACKNOWLEDGMENT}

The authors thank Penelope K. Elias, PhD, and Amanda L. Goodell, MA (University of Maine), for valuable technical editorial suggestions.

\section{DISCLOSURE}

Dr. Elias is a salaried principal investigator on NIH/NHLBI R01HL081290; has received honoraria from the NIH for research grant reviews; has received royalties from Taylor and Francis Publishing
Company, UK, for editorial and author responsibilities (Experimental Aging Research); has served as a consultant for The University of Georgia Centenarian Study; and has received funding for travel to scientific meetings from the NIH and the University of Maine. Dr. Davey served on a scientific advisory board for the Longitudinal Aging Study Amsterdam; receives royalties from publishing Caregiving Contexts (Springer Publishing Company, 2008); has received honoraria from the NIH and AOA for research grant reviews; and has received research support from the NIH/ NIA [1P01-AG17553 (Core Coleader Data Management and Analysis), 1R01-AG24045 (Coinvestigator), and 1R01-AG13180 (Co-PI)].

\section{REFERENCES}

1. Oulhaj A, Wilcock GK, Smith AD, de Jager CA. Predicting the time of conversion to $\mathrm{MCI}$ in the elderly: role of verbal expression and learning. Neurology 2009;73:14361442.

2. Snowdon DA, Kemper SJ, Mortimer JA, Greiner LH, Wekstein DR, Markesbery WR. Lingusitic ability in early life and cognitive function and Alzheimer's disease in late life: findings from the nun study. JAMA 1996;275:528532.

3. Greifennhagen A, Kurz A, Wiseman M, Haupt M, Zimmer R. Cognitive assessment in Alzheimer's disease: what does the CAMCOG assess? Int J Geriatr Psychiatry 1994; 9:743-750.

4. Bowler JV. Modern concept of vascular cognitive impairment. Br Med Bull 2007;83:291-305.

5. Fisk JD, Rockwood K. Outcomes of incident mild cognitive impairment in relation to case definition. J Neurol Neurosurg Psychiatry 2005;76:1175-1177.

6. Knopman DS, Mosley TH, Catellier DJ, Coker LH, for the Atherosclerosis Risk in Communities Study Brain MRI Study. Fourteen-year longitudinal study of vascular risk factors, APOE genotype, and cognition: the ARIC MRI Study. Alzheimers Dement 2009;5:207-214.

7. Razay G, Williams J, King E, Smith AD, Wilcock G. Blood pressure, dementia and Alzheimer's disease: the OPTIMA Longitudinal Study. Dement Geriatr Cogn Disord 2009;28:70-74.

8. Clarke R, Smith AD, Jobst KA, Refsum H, Sutton L, Ueland PM. Folate, vitamin B12, and serum total homocysteine levels in confirmed Alzheimer disease. Arch Neurol 1998;55:1449-1455.

9. Cronbach LJ, Meehl PE. Construct validity in psychological tests. Psychol Bull 1955;52:281-302.

10. Boring EG. A History of Experimental Psychology. New York: Appleton-Century-Crofts; 1929:196. 